\title{
NOTA DOS EDITORES
}

É com satisfação que a Antropolitica - Revista Contemporânea de Antropologia, vinculada ao Programa de Pós-graduação em Antropologia da Universidade Federal Fluminense, apresenta o seu número 52, neste segundo trimestre de 2021.

Em primeiro lugar, introduzimos o dossiê "Um mundo em recomposição: uma análise antropológica das novas formas de regulação e certificação dos objetos e pessoas na contemporaneidade". O dossiê foi proposto e organizado pelos professores Hully Guedes Falcão (UFF), Fabio Reis Mota (UFF), Manuela Vieira Blanc (UFES) e Gabriela Cuervo (UFF). Ele é resultado de um trabalho em rede, nacional e internacional, de produção de pesquisas e discussões teóricas e metodológicas que propõem romper "com as tradicionais operações de divisão social científica em que a Europa produz as teorias e a periferia as consome". O dossiê inicia com o artigo de apresentação dos seus organizadores, no qual apresentam as discussões centrais da proposta e as principais relações entre os oito artigos selecionados e publicados. Apesar dos diversos campos empíricos abordados, as discussões se entrelaçam em torno da análise das operações críticas e das provas às quais os atores são submetidos nas mais variadas situações (cívicas, morais, legais etc.) constitutivas das sociedades complexas atuais e que outorgam formas e sentidos diversos as suas demandas, modos de tratamento e de reconhecimento no espaço público.

Além desse debate, o presente número da Antropolítica possui cinco artigos de temática livre, oriundos do fluxo contínuo da revista, e um artigo na seção "Trajetórias e Perspectivas". Por fim, incluímos também uma resenha de um livro da área.

Iniciamos com $o$ artigo "Refúgio e família: entre mulheres do conflito sírio no Brasil e Tunísia”, da antropóloga Mirian Alves de Souza, da Universidade Federal Fluminense. A partir de uma etnografia com pessoas refugiadas do conflito sírio, o artigo aborda narrativas de mulheres no Brasil e na Tunísia com o objetivo de enriquecer a produção antropológica no campo da migração forçada. Com base em uma perspectiva comparada, o trabalho traz contribuições campo dos estudos sobre família e refúgio, em especial a partir da descrição das relações familiares anteriores e durante o deslocamento.

$\mathrm{O}$ artigo seguinte intitula-se "A PEC 55/2016 e o medo que dela sobrevém: Agenciamentos, disputas e enquadramentos no ativismo em HIV/Aids", de autoria do antropólogo Ricardo Andrade Coitinho Filho, da Universidade Federal Fluminense. A partir do acompanhamento etnográfico de uma rede de jovens que vivem e/ou convivem com HIV/Aids na interseção com 
outros coletivos, o autor analisa as estratégias, ações e disputas presentes nas demandas por reconhecimento no movimento social em HIV/Aids, frente ao estigma que ainda permeia as concepções sobre a doença e os sujeitos a ela associados. Nessa perspectiva, Coitinho Filho busca entender como os participantes do movimento que se identificam como ativistas têm atribuído sentido a essa forma de atuação e de que maneira ela pode se desdobrar na produção de um repertório ativista emergente.

Em seguida, o artigo "Concepções de justiça compartilhadas: a negociação pelos danos espirituais ao povo Mẽbêngôkre Kayapó”, é de autoria conjunta de Lucas Cravo de Oliveira, Douglas Antônio Rocha Pinheiro, ambos da Universidade de Brasília, e Ronaldo Joaquim da Silveira Lobão, da Universidade Federal Fluminense. Colocando em diálogo a antropologia e o direito, os autores buscam compreender a maneira como o constitucionalismo brasileiro cria possibilidades no sistema de justiça para se administrar um conflito no qual se entrecruzam diversas concepções de justiça. $\mathrm{O}$ artigo toma por base um estudo de caso sobre o processo extrajudicial decorrente da queda do Voo 1907 da empresa aérea Gol na Terra Indígena Capoto-Jarina, do qual decorreu uma indenização diferenciada para o povo indígena Mẽbêngôkre Kayapó. Assim, os autores discutem a categoria de "danos culturais" e as discussões sobre os seus sentidos ao longo do processo em relação a outras denominações, como danos socioculturais ou espirituais.

O artigo seguinte, “'Esquadrão da Morte', 'grupos de extermínio' e os movimentos sociais: mudanças em uma categoria da 'Violência Urbana'”, de David Maciel de Mello Neto, da Universidade Federal do Rio de Janeiro, discute o impacto da atuação de movimentos sociais na reformulação e redefinição das categorias grifadas no título do trabalho. A partir de um conjunto de conceitos analíticos tomados da sociologia e da antropologia, de autores como Charles Tilly, Sidney Tarrow, Olivier de Sardan e Max Gluckman, o autor discute as mudanças no campo da "violência urbana" e os seus efeitos políticos e sociais oriundos delas. Especial atenção é dada para a atuação dos movimentos sociais e o seu potencial transformador.

Por fim, o artigo "Poder Judiciário e combate à corrupção: atuação e discursos do Tribunal Regional Federal da $4^{\mathrm{a}}$ região", de Marina Balestrin Kobielski, pesquisadora autônoma, e Rodrigo Ghiringhelli de Azevedo, da Universidade Católica do Rio Grande do Sul, propõe analisar se, tendo em vista as grandes operações policiais mais recentes, como a Operação Lava-Jato mudou o padrão de decisões do Judiciário. Tomando como base a atuação do Tribunal Regional Federal da $4^{\text {a }}$ Região nos crimes de corrupção ativa e passiva durante todo o ano de 2018, os autores tratam de questões sociológicas relevantes, tais como a judicialização da política e o combate à corrupção no Brasil contemporâneo. 
A publicação seguinte corresponde à seção "Trajetórias e Perspectivas". A seção contempla artigos e ensaios que abordem reflexões sobre o fazer antropológico, a partir das experiências e trajetórias de antropólogos brasileiros e estrangeiros, bem como do histórico de constituição e/ou consolidação de áreas ou campos de pesquisa no Brasil e no exterior. Neste número, publicamos a tradução ao português do artigo Une brèche critique dans la ville garantie? Espaces intercalaires et architectures d'usage - "Uma brecha crítica na "cidade garantida"? Espaços intermediários e arquiteturas de uso" - , de autoria de Marc Breviglieri e cuja tradução foi realizada pela antropóloga Yolanda Gaffrée Ribeiro. O artigo, originalmente publicado na coletânea Le quartier des Grottes/Genève: De La différence urbaine, organizada por Lanza, Cogato, Pattaroni, Piraud e Tirone e publicada pela Editoria Métis Presses, da Suíça, em 2013, compartilha uma proposta de abordagem das metrópoles contemporâneas, o direito à cidade, os circuitos, espaços e escalas contidos nelas.

Por fim, o número 52 da Antropolítca traz a resenha da obra Hated and Proud: Ultras Contra Modernity, de Mark Dyal, publicada em 2018 pela Editora Arktos, em Londres. A resenha, elaborada por Vinícius Teixeira Pinto, da Universidade Federal do Rio Grande do Sul, apresenta a etnografia de Dyal realizada com grupos de torcedores Ultras da Roma, tradicional clube do futebol italiano, bem como as relações estabelecidas por eles com outros rivais, com o Estado e outros agentes do mundo do futebol. Dessa forma, Pinto busca promover a discussão dessa obra no Brasil, destacando o seu potencial no campo das pesquisas e debates sobre as torcidas organizadas de futebol no país e suas práticas do torcer.

A imagem de capa, escolhida pelos organizadores do dossiê, trata-se de uma readaptação/recriação de uma obra produzida, em 2011, pelo artista Pedro Silva Valle, a partir de colagens digitais. A readaptação foi realizada gentilmente por Pedro para adaptar a ilustração ao formato gráfico da revista e se aproximar ainda mais da proposta do dossiê.

Devido à complexidade da temática do dossiê e a diversidade de questões apresentadas nos artigos, optamos por trazer na capa uma ilustração provocativa e capaz de gerar impressões a partir da perspectiva das leitoras e leitores, sem perder a conexão com a proposta. A obra, de inspiração surrealista, apresenta uma composição de elementos que sugere um universo de normatizações e controles sendo apropriados de múltiplas formas, a partir dos valores, referências e afetos dos atores humanos em questão. Além disso, remete às múltiplas agências (humanas e não humanas) conectadas e articuladas nestes (re)arranjos: aparatos tecnológicos, instrumentos de pesquisa, meios de comunicação, plataformas digitais, humanos com suas readaptações, ressignificações, afetos e performances.

A ideia de trazer uma obra de inspiração surrealista para representar imageticamente 
este dossiê está em consonância, sobretudo, com a orientação teórica e metodológica dos trabalhos apresentados, cujas análises concentram-se na capacidade crítica dos atores em refletir sobre as contingências nas quais estão inseridos e reelaborar suas vivências e práticas a partir de seus quadros de referência morais, cognitivos e afetivos.

Para finalizar, lembramos a todos que continuamos a receber submissões para a área das Ciências Sociais, em especial no campo da Antropologia, em fluxo contínuo, no endereço http://www.revistas.uff.br/index.php/antropolitica, no qual podem ser encontradas as normas de publicação e outras informações. Mantemos o nosso e-mail (antropoliticauff@gmail.com) para eventual contato. Sugerimos também acompanhar nossas notícias também através do perfil no Facebook,Instagram (@antropoliticauff)enoTwitter(@RAntropolitica).

Boa leitura! 